\title{
El atractivo de las ciudades medias*
}

\section{Leonard Plotnicov * *}

En este trabajo se descarta, primero, el concepto y las ideas en torno a la clasificación de las ciudades como medianas. Se establece la relación de éstas con la ciudad principal y se estima la atracción de residentes de esta última hacia las primeras como una razón de política para justificar la atención que el gobierno debería otorgarles.

En la segunda parte del trabajo, y considerando las ventajas de localización que ofrecen las ciudades de la parte centro del norte de México, se hace una propuesta para captar un segmento del mercado de consumo y del gasto disponible del grupo de población de la tercera edad en Estados Unidos, que es uno de los que experimenta un mayor crecimiento absoluto y relativo y las implicaciones que esto tendría para la fuerza de trabajo, los inversionistas y los gobiernos federal, estatal y local de esta región.

El argumento que subyace en todo el trabajo es el de la cada vez mayor necesidad de oportunidades para cruzar barreras disciplinarias y póder aplicar los conocimientos en la resolución de problemas que afectan en la actualidad a las sociedades regionales.

Antes de participar en este simposio no me había encontrado con la expresión ciudades medias. Así, cuando se me invitó a presentar mis opiniones al respecto, recordé la broma de Horace Miner (1967: 3) cuando dice que "todo mundo sabe lo que es una ciudad, menos los expertos". Al no saber qué era una ciudad media, concluí que, con base en el criterio de Miner, yo debía ser un experto en el tema y tener la capacidad, por lo tanto, de otorgar comentarios clave. Desde entonces me he enterado de que, en México, la expresión a menudo se emplea en oposición a la ciudad de México. ${ }^{1}$

Cuando acepté presentar este documento, también dudaba de por qué los organizadores del simposio habían escogido las ciuda-

* Una versión anterior de este texto se presentó durante el XIII Congreso Internacional de las Ciencias Antropológica y Etnológica (CICAE), celebrado en la ciudad de México del 29 de julio al 4 de agosto de 1992. Agradezco a la doctora Carmen Icazuriaga Montes, al doctor Boris Graizbord y a El Colegio de México por invitarme a exponer en su simposio acerca de las ciudades medianas y por su cálida hospitalidad. Hago extensivos estos agradecimientos al resto de los participantes del simposio por sus valiosos comentarios que ayudaron a completar este ensayo (Traducción de Gilberto Conde).

* * Universidad de Pittsburgh.

1 Sería interesante saber si el término de medio contiene connotaciones de valor implícitas que lo hagan preferible a otros. ¿Tendrá más atractivo? 
des medias como tema central. ¿Por qué no optaron por discutir sobre las ciudades gigantescas si claramente auguran el futuro? ¿Por qué no las pequeñas? Ese tema podría ofrecer argumentos divertidos, aunque fútiles, sobre las diferencias entre ellas y las grandes, de circunscribirse a evaluaciones numéricas. Centrar la discusión en diferencias importantes acerca de sus funciones críticas también podría haber resultado estimulante y esclarecedor desde el punto de vista teórico.

Me llegó la inspiración cuando noté que el programa incluía una serie de reportes de investigación urbana en México, y la mayoría se refería a lo que podría considerarse como ciudades pequeñas. Esto daba a entender que la opción de los organizadores por las ciudades medias se inspiraba en una preocupación por la talla y los problemas de la ciudad de México y permitía adivinar su razonamiento, si las ciudades medias eran un sitio atractivo de residencia alternativo al Distrito Federal, podrían constituir un medio para contener el crecimiento de éste.

Estas suposiciones han dado forma a mis comentarios y estimulado una proposición práctica para ocuparse de las dimensiones de la capital mexicana. Asimismo, me parece útil tomar en serio la cita de Miner sobre los expertos en urbanismo y reflexionar acerca del significado de algunos conceptos fundamentales para el tema del simposio. Empecemos por ver las implicaciones de que una ciudad no sea ni pequeña ni grande, sino media.

\section{Dimensiones urbanas}

Definir una ciudad como media resulta más difícil de lo que se podría pensar. No se trata simplemente de declarar que su tamaño se encuentra entre el de las pequeñas y las grandes. Es menester comenzar por decidir si la categoría debe ser relativa o absoluta; es decir, si una ciudad media es relativa a una región o nación, o si la determinación se hace con una escala numérica, independiente de las diferencias regionales o nacionales. Aquélla limita la comparación a una zona, mientras que los valores numéricos ofrecen una medida que puede aplicarse umiversalmente. ${ }^{2} \mathrm{En}$ cualquier caso, la talla media puede determinarse únicamente en relación con las ciudades grandes, ya que la diferencia entre

2 Douglas White, en este volumen, se sirve de un criterio numérico absoluto para definir las ciudades medianas. A mi manera de ver las cosas, una ciudad media es para él aquella cuyas dimensiones no exceden la capacidad de su programa de computadora para graficar las redes sociales de las élites locales. 
las pequeñas y los pueblos grandes es ambigua. Las ciudades grandes no implican ambigüedad alguna, pero las pequeñas sí forman una categoría difusa.

Referirse al lado menor del continuo urbano para definir la talla media representa una dificultad similar por el poco acuerdo existente respecto de la población mínima para designar un sitio como urbano. Cada gobierno nacional lo determina arbitrariamente. Estas cifras y los criterios que determinaron su decisión no pueden utilizarse para realizar comparaciones interculturales, ya que son inconsistentes al relacionarse con las particularidades regionales o nacionales. Por ejemplo, los países escandinavos definen como ciudad cualquier asentamiento con una población de doscientos o trescientos habitantes. En países muy poblados, cifras tan pequeñas describirían un pueblo; pero en regiones escasamente pobladas, como Noruega, Australia y Alaska, los lugares pequeños adquieren importantes funciones centrales. Análogamente, y precisamente porque varía de un lugar a otro, la medida absoluta de las dimensiones mínimas para definir una ciudad también cambia con el tiempo. Lo que hoy es medio en el pasado era enorme.

Las fórmulas para determinar las categorías de las magnitudes urbanas se pueden calcular objetivamente y con precisión numérica; pero la manera más fácil de lograr una división racional es con una distribución de asentamientos rango-tamaño. Estas distribuciones, sin embargo, no están presentes en todas partes, sino que tienden a aparecer en los países más grandes, así como en los que cuentan con una larga historia de urbanización (Berry, 1961). Aun así, no faltan las excepciones.

Algunos países pequeños, como Corea y El Salvador, tienen una distribución de rango-tamaño, mientras otros grandes, en población o extensión física como Gran Bretaña, Canadá y Australia, carecen de ciudades medias. Por otro lado, algunos países con una larga historia de urbanización ( $v$. gr. México, Irak, Egipto) exhiben un patrón de ciudad principal, en el que la ciudad mayor del país es varias veces mayor a las que quedan en segundo lugar. Esta distribución dificulta establecer lo intermedio. La bibliografía acerca de patrones de distribución por talla da la impresión a veces de que el curso preferible de desarrollo sería una regla de distribución rango-tamaño, mientras que un patrón de primacía sería anormal y poco sano, en especial donde las ciudades principales son inmensas. ${ }^{3}$ Con todo, los tres patrones de distribución

${ }^{3}$ Dado el lugar de la conferencia, Teotihuacán ofrece un excelente ejemplo de una ciudad principal antigua. Durante su esplendor (circa 200 a.C. - 750 d.C.) fue 
-rango-tamaño, primacía y centro vacío- aparecen en el mundo con aproximadamente la misma frecuencia, lo que ha llevado a Hartshorn (1992: 63) a concluir que "no existe una explicación razonable y global de las condiciones asociadas con cada uno de estos tipos de distribución".

Quizás (y pidiendo disculpas a Horace Miner) sólo los expertos puedan llegar a la conclusión lógica de que no existe tal cosa como una ciudad media. A pesar de esta sofisticación, los expertos entienden, por supuesto, que las dimensiones de una ciudad, como cualquier otra cosa graduada, constituyen elucubraciones decididas de manera arbitraria. En otras palabras, podemos definir una ciudad mediana de cualquier manera que queramos, siempre que expresemos clara y abiertamente nuestras motivaciones y propósito para optar por una definición dada. Obviamente, el objetivo en este caso parte de la preocupación por el crecimiento y el tamaño de la ciudad de México, junto con la creencia y esperanza de que las ciudades mexicanas de menores dimensiones puedan ayudar a disminuir la presión de la población allá, al atraer el crecimiento hacia sí.

La meta de ejercer cierto tipo de control sobre la distribución de la población nacional provee otro marco de referencia más para determinar "lo medio". Así, es legítimo y razonable afirmar que existen dos categorías de dimensión de la ciudad en México. Como indicaba anteriormente, con esto podemos definir lo que queramos. Propongo que establezcamos una categoría, con sólo un ejemplo, de ciudad principal (dado que su utilización es extendida y aceptada). Todo sitio urbano aparte de la ciudad de México serán las ciudades medias. Esta clasificación es consistente con la manera en que se delinean las taxonomías y satisfacerá las exigencias más severas de la ciencia. Lo que importa a final de cuentas, por supuesto, es cuán bien nos sirven los conceptos para comprender y resolver los problemas sociales.

Los conceptos, sin embargo, en ocasiones son engañosos. Por ejemplo, otrora se consideraba que los patrones de distribución de rango-tamaño constituían el curso normal del desarrollo urbano. En lugar de existir este patrón en América Latina, lo más común son las ciudades principales (Harris, 1971: 178; Hardoy, 1975.) Aunque hay correlación entre las ciudades principales de la zona y los problemas de desarrollo urbano, no se puede con-

única por su :iagnitud (más de cien mil habitantes) y su localización (el México central) ante la ausencia de asentamientos circunvecinos numerosos. Pocas ciudades de la antigüedad se comparan con ella por longevidaç o tamaño, así que difícilmente se le puede caracterizar de experimento patologico o fallido. 
cluir de ello la existencia de una relación causal entre desarrollo y patrones de distribución de asentamientos. Con todo, se da crédito de factor causal al patrón de asentamiento cuando se relaciona con magnitudes enormes y crecimiento rápido. Se toma una ciudad principal de gran tamaño como indicador de sobreurbanización, lo que Castells (1977: 41-43) llama "un nivel de urbanización superior al que normalmente se puede alcanzar dado el nivel de industrialización". Esto podría significar que una ciudad tenga más habitantes de los que puede atender la economía; pero aceptemos que se busque decir que hay más gente de la que puede ser mantenida con una calidad de vida satisfactoria. 4

Una noción relacionada con lo anterior es la de urbanización falsa, es decir, que la urbanización no es tanto conducida por una economía industrial en expansión, sino sobre todo por un crecimiento rápido de la población. Ambos términos, urbanización falsa y sobreurbanización, conllevan una condición en que la tasa de crecimiento de la población urbana rebasa el ritmo del desarrollo económico. Ambos conceptos son fundamentalmente subjetivos y tienden a desviar la atención del hecho de que esta condición se aplica igualmente a las zonas rurales. En éstas, la tasa de crecimiento de la población es superior a la de desarrollo económico. Se podría igualmente llamar sobreruralización a este proceso, con la ventaja de orientar la atención a causas más que a síntomas, pero no se pronuncia con facilidad. El meollo del problema es que hay demasiada gente dependiente de los recursos y la tecnología disponibles en las áreas rurales. Al igual que el trabajo excedente. las personas se ven obligadas a buscar empleo en pueblos y ciudades (Laquian, 1982: 68). Con la extensión de la tecnología agrícola automática, se puede esperar que estas condiciones se incrementen. Estoy muy consciente de que otros ven las fuentes del problema en la casualidad o la falta de medidas de control de la natalidad; oero podríamos asimismo culpar a la mayor esperanza de vida y las menores tasas de mortalidad infantil.

\section{Megaciudades}

Las ciudades con diez millones de habitantes o más, las megaciudades, constituyen los ejemplos más sobresalientes de lo que el

\footnotetext{
4 El término prejuicia el caso con las connotaciones negativas del exceso y, en cualquier caso, probablemente lo introdujeron Davis y Golden (1954) en una época en que los observadores carecían de una apreciación de la importancia de la economía subterránea o informal.
} 
término sobreurbanización trae a la mente. Existen en nuestros días cerca de dos docenas de megaciudades, casi todas en países de urbanización rápida y con altas tasas de natalidad. Pronto habrá muchas más. Se calcula que la población mundial alcanzará los 6 mil millones de habitantes para el 2000, la mitad localizada en urbes. Alrededor de $\mathbf{8 0} \%$ de las mayores ciudades del próximo siglo se encuentra en países en desarrollo, eufemismo para referirse a los países más pobres que el promedio. Se pronostica que la ciudad de México, con una población actual de entre 15 y 18 millones, ${ }^{5}$ o cerca de la quinta parte de la población total del país, seguirá siendo la mayor, con entre 25 y 30 millones de habitantes.

Las megaciudades tienen la reputación de pecar de problemas especiales debidos a su mayor tamaño. Empero, muchos de los males que se les atribuyen, como la pobreza y el hacinamiento, han sido parte de la vida urbana durante miles de años y no se deben a la talla ni a la escala. Otros problemas, como delincuencia y congestionamientos de tráfico, pueden ser igualmente viejos, e igual que los otros dos, los comparten ciudades menores. Estos atributos supuestamente son peores en las megaciudades, donde la salud humana también sufre de mayores daños a causa del deterioro ambiental. Las ya pesadas atmósferas de algunas megaciudades parecen haber alcanzado, o al menos se acercan a ello, sus límites para tolerar más toneladas de contaminantes. Muchas apenas son capaces de mejorar su infraestructura para satisfacer sus necesidades en aumento constante. Un abasto energético inadecuado es fastidioso; un suministro de agua inapropiado es peligroso. 6

No todas las megaciudades son iguales. Ponerlas todas en un mismo montón equivale a poner un signo de igual entre ballenas y elefantes. Existe una diferencia importante entre, digamos, Río de Janeiro o São Paulo, por un lado, y Nueva York o Tokio, por el otro. La diferencia reside en la riqueza. El tamaño en sí es secun-

${ }^{5}$ Estas cifras se refieren a la zona metropolitana. Harris (1971) ofrece información demográfica histórica de la ciudad de México.

6 Gulick (1989: 5, ff.) hace la aclaración importante de que las ciudades, a lo largo de la historia, han estado sujetas a un sesgo antiurbano, y Plotnicov (1970) ofrece una explicación. Sin embargo, no deja de ser cierto que las ciudades, independientemente de su tamaño, sí tienen sus problemas. Algunos observadores, al referirse a las barriadas, la pobreza, el abuso de las drogas y el alcohol, y el número creciente de personas sin hogar, mayores tasas de crimen violento y sin sentido, transporte público y sistema educativo inadecuados, deterioro físico y ambiental, reducción de los servicios públicos, policía irresponsable, corrupción política, bancarrota fiscal, estallidos raciales, etcétera, hacen al escenario actual lo suficientemente alarmante para definirlo como de crisis (Steinberger, 1985). 
dario. Salta a la vista que la riqueza nacional es mucho más importante que las dimensiones si operamos un ligero viraje cognoscitivo para ver una megalópolis (Gottman, 1961) como una ciudad y no como un montón de municipios. Pensar las megalópolis como megaciudades genera muchos más casos, y casi todos en países industriales avanzados. Por costumbre, sin embargo, restringimos nuestro concepto de ciudad a una entidad política, con un solo nombre y límites definidos arbitrariamente.

Las megaciudades captan nuestra atención por ser tan grandes y haberse extendido tan rápidamente. Se dice que llegan a El Cairo 1000 migrantes por semana, subestimando quizás el flujo real. La urbanización rápida pone bajo presión los recursos financieros de las naciones más pobres. Sus gobiernos no pueden encarar los requerimientos de infraestructura y servicios municipales suplementarios. Esfuerzos honestos por hacerlo rápidamente se ven afectados por aumentos en el número de habitantes, de manera que tratar de cerrar la brecha entre las necesidades y la habilidad para satisfacerlas es como buscar pegarle a un blanco en movimiento.

A pesar de los defectos de las megaciudades, los migrantes las prefieren sobre otros lugares. Con información anecdótica de Kandell (1985), Gulick (1989: 47-48) reporta que los muy pobres de la ciudad de México ven su vida allí de manera positiva al compararla con las condiciones que según sus conocimientos o creencias existen en ciudades más pequeñas y zonas rurales. Dicen que México les ofrece una ventaja importante, mayores oportunidades de empleo con buen sueldo. Para muchos, el agua corriente y un sanitario con agua constituyen servicios públicos novedosos y más que convenientes. Esto también representa indicios de avance personal y apoya la creencia en un futuro mejor para sus hijos.?

Ciudades de 25 o 30 millones serán lugar común dentro de cien años a causa de los avances de la tecnología. Eso debe pasar a menos de que la tendencia de la historia urbana de los últimos seiscientos años dé un viraje sin precedentes. Suponiendo que el crecimiento continuo fuese una condición inalterable durante los próximos 30 años, ¿cuánta gente será conducida a vivir afuera de las zonas sobrepobladas si este ajuste no lo opera una mano invisible o malthusiana?

\footnotetext{
${ }^{7} \mathrm{Me}$ baso en lo que parece ser la opinión general de que el actual crecimiento de la ciudad de México se debe a la migración. Véase, sin embargo, Arriaga (1968: 242 ), quien argumenta que su crecimiento se debe menos a la migración que al crecimiento natural.
} 


\section{Redistribución de la población}

La idea de sacar gente de las grandes ciudades para crear ciudades medias aparece en el movimiento de las ciudades jardín en Inglaterra durante el siglo pasado, y más recientemente, en los intentos de Brasil y Nigeria por mudar sus hacinadas capitales de la costa a sitios más centrales en el interior. Así, Nigeria y Brasil esperaban separar las actividades comerciales de las administrativas y estimular el crecimiento económico en las zonas subdesarrolladas de sus países. El proyecto de cambiar la capital nigeriana de Lagos a Abuja fue diseñado antes de la caída de los ingresos por las exportaciones petroleras. Se han detenido las obras, para posponer indefinidamente la fecha para terminarlo. La mala suerte (y en gran medida mala administración) de Nigeria nos impide saber qué resultados habría tenido este experimento. Brasilia, inaugurada en 1957, se encuentra a 700 millas de la antigua capital, Río de Janeiro. Originalmente, se había fijado la meta de alcanzar los dos millones de habitantes para el año 2000 , mas ya cuenta con $4 \mathrm{mi}$ llones, con un incremento de $\mathbf{1 0} \%$ anual, habitada casi en su totalidad por gente pobre en cinturones de miseria. Brasilia ha tenido bastante éxito en la atracción de pobladores.

Abundante evidencia indica que la gente suele ser reacia a migrar, y prefiere pasar sus vidas en donde nació y creció. Por lo general sólo se muda cuando no le queda más alternativa.

La gente común puede superar barreras políticas e incluso logra cruzar fronteras con cercas de púas o ríos sucios; pero la desesperación de su "opción" no refleja tanto su habilidad para mudarse como la intensidad de la "presión que los empujó y puso en movimiento" (Logan y Molotch, 1987: 41).

Cambiarse representa una decisión de vida de grandes consecuencias, y sólo se emprende por razones de peso. A menudo se hace de forma involuntaria, como en el caso de refugiados o gente expulsada de sus asentamientos. En sentido figurado y literario, la gente se ha visto motivada a migrar por ideales políticos y religiosos. La atracción de visiones religiosas y utópicas de una ciudad mejor vio a docenas de nuevas comunidades establecerse en Estados Unidos durante el siglo xIx, y tales comunidades (o comunas) siguen apareciendo en nuestros días.

El movimiento británico de las ciudades jardín, iniciado a fines del siglo xix, estaba imbuido de entusiasmo. Surgió en respuesta al rápido crecimiento urbano proveniente de la Revolución Industrial, aunque más directamente de las condiciones deplorables existentes en Londres, la megaciudad del momento. Ebenezer Howard, el visionario del movimiento, esperaba atraer 
gente a sus nuevas ciudades ofreciéndoles un ambiente más sano, que combinara los mejores aspectos de la vida rural y la urbana, y que encarnara sus ideales políticos liberales. Los residentes, por ejemplo, provendrían de todas las profesiones y clases sociales. Serían propietarios colectivos de los bienes raíces y de las instalaciones municipales de la ciudad, y se gobernarían por medios democráticos. Con el fin de animar la democracia y cultivar un sentido de la vida comunitaria -vista como dos lados de la misma moneda- las ciudades jardín, idealmente, debían tener alrededor de 30000 habitantes. Todo crecimiento suplementario sería regulado con situar la ciudad en el campo, rodeándola por un cinturón de tierras agrícolas capaces de permanecer intactas o transformarse en desarrollo urbano.

Sólo se construyeron dos ciudades jardín, de modo que el esfuerzo tuvo pocas consecuencias en un Londres en expansión. Sin embargo, las ideas de Howard -como relacionar el tamaño de la ciudad y sus características arquitectónicas con el sentido humano de las proporciones, y la preocupación por fomentar un sentido tradicional de la comunidad-siguen inspirando a arquitectos y planificadores urbanos en todo el mundo.

Durante la depresión de los años treinta, el gobierno de Estados Unidos financió la construcción de algunas ciudades con cinturones verdes, no tanto para desahogar el excesivo hacinamiento, sino para crear empleos. Los tres casos más conocidos, Irvine en California, Reston en Virginia y Columbia en Maryland, fueron construidos por empresas privadas que trataban de apegarse a algunos de los principios de Howard, como mantener la heterogeneidad de clase y fijar límites al crecimiento. Estas atractivas comunidades se construyeron para un mercado selectivo (Glaab y Brown, 1992).

Reston, con una población de unos 70000 habitantes, y Columbia, con más de 100000 , son suburbios de Washington, D.C., al igual que en Irvine, su diseño incluía normas específicas de buen gusto en la planificación arquitectónica y urbana. Las tres se sitúan cerca de universidades importantes, ya que atraen sobre todo a científicos y académicos. Estas comunidades son atractivas, pero nunca se pretendió que constituyeran válvulas de escape para regular la población. Ha habido, con todo, algunos intentos recientes por hacer precisamente eso.

El gobierno egipcio buscaba quitar algo de la presión de El Cairo al crear nuevos asentamientos cerca del delta del Nilo y, hacia el oeste, a lo largo de la costa del Mediterráneo. Según la prensa, estos pueblos atrajeron a pocos debido a que se sitúan lejos de los centros de empleo, es decir, El Cairo y Alejandría. 
Hace unos 25 años, el gobierno japonés construyó Tsukuba, un parque de investigaciones y una comunidad residencial a unas 50 millas al norte de Tokio. Con una nueva universidad, agencias gubernamentales de investigación, y vivienda para clase media, se buscaba que fuera una ciudad pequeña para científicos y personal docente. Únicamente 25 mil personas han poblado el lugar, menos del número de expectadores de un juego de baseball en Tokio. Muchos de los empleados de la universidad o de las dependencias gubernamentales siguen viviendo en la capital y se desplazan diariamente para trabajar (Gulick, 1989: 83).

Algunos colegas familiarizados con Tsukuba dicen que, según el gobierno este proyecto es exitoso, y explican que promueve el establecimiento de contactos entre académicos e industriales para la formulación de planes de investigación pura y aplicada, muy similar al Parque Industrial de Stanford en California y el Parque del Triángulo de Investigación en el norte de Carolina. Empero, los residentes de Tsukuba suelen ser profesionistas jóvenes. Los mayores tienden a permanecer en Tokio por dos motivos. Han llegado a un momento de sus vidas en que cargan con responsabilidades familiares y comunitarias, y suelen vivir con padres de edad avanzada cuya casa piensan heredar. Tokio es también el sitio donde han establecido sus redes de contactos profesionales, obtienen trabajos suplementarios y dan asesoría.

La creación de nuevas ciudades como Brasilia y Tsukuba ofrece a los planificadores y arquitectos la oportunidad de diseñar sitios urbanos de gran belleza. Parques, estadios, museos, salas de conciertos, bulevares, plazas y otros servicios públicos y mejoramientos que otorgan a la ciudad su carácter y encanto distintivo. Esta infraestructura y detalles deseables son bien recibidos, aunque su importancia no deja de ser de segundo orden cuando se trata de atraer a nuevos habitantes. La gente emigra cuando la obligan factores políticos, sociales, económicos y de otro tipo, y cuando no bajo coerción, más por motivos económicos que de otra índole. "Primero que nada, la gente debe vivir donde pueda encontrar trabajo" (Logan y Molotch, 1987: 41).

\section{Cambios en la disciplina}

En este punto de la presentación, los antropólogos de años anteriores habrían resumido los puntos principales, reiterado la importancia de los incentivos económicos para desviar a los migrantes de las megaciudades y presentado sus conclusiones con una nota, ya fuera pesimista, ya optimista. Con todo, eso era así cuan- 
do la distinción analítica entre la teoría y la práctica se rectificaba y se sostenía como inviolable. Aunque los antropólogos empezaron a llevar la teoría a la práctica en los años treinta, y la antropología aplicada fue importante desde el punto de vista militar durante la segunda guerra mundial, así como para redactar posteriormente las condiciones de paz, tomó varias décadas más borrar por completo el estigma atribuido al trabajo aplicado. Si sirve de indicador preciso el hecho de que un ex director de la Asociación Americana de Antropología dicte una "ponencia distinguida" a la Sección de Antropología General de la Asociación, entonces la actitud de la profesión hacia la dualidad teoría-práctica ha dado un giro de 180 grados. Ignorar cualquier distinción entre el teórico y el práctico y hacer eco de un llamado escuchado cada vez con mayor frecuencia, Rappaport (1993) incita a todos los miembros de la Asociación a representar una antropología comprometida y responsable. Por ahora, tomo su mensaje para decir que es menester no quedarse en señalar lo que anda mal o por qué algo no funcionará, y ofrecer propuestas concretas. Aunque éstas no fueran prácticas o realistas, pueden ser útiles para permitir idear mejores esquemas.

Cambios como el anterior atestiguan cómo se desdibujan las fronteras disciplinarias y se hacen mạ́s permeables. Economistas, planificadores urbanos y antropólogos ahora se conducen más por los problemas que por las orientaciones de sus disciplinas. Se ha dado una transformación paralela en la toma de decisiones empresariales en el sentido de restar énfasis a la compartimentación del especialista a favor de la generalización multidisciplinaria. Mitroff y Linstone (1993) llaman a esto, "reflexión por sistemas sin fronteras". Ayuda a crear un ambiente que supera las limitaciones de las maneras habituales de pensar para ofrecer más libertad y flexibilidad a la manera en que se asumen los problemas.

También podríamos dar la bienvenida a esta mayor tolerancia para traspasar las fronteras de las disciplinas, ya que alienta a no limitarse a declarar qué principios gobiernan el crecimiento urbano, sino ofrecer asimismo, propuestas concretas que puedan darnos un mayor control sobre el proceso. Al ofrecer algunas ideas que relacionan la ciudad de México con las ciudades medias, entro conscientemente en áreas en que mi ignorancia va de grande a suprema, pero confiando en que mis palabras serán tomadas con un ánimo de tolerancia intelectual. 


\section{Un propuesta modesta}

Como no podemos depender de acontecimientos fortuitos, como descubrir una veta de oro o un mar de petróleo bajo nuestros pies, la creación de condiciones para atraer nuevos habitantes, provenientes de zonas sobrepobladas a otras, requiere de medidas deliberadas. Es decir, las áreas designadas para el asentamiento necesitan mejorar sus economías, y presumiblemente, hacerlo bajo las condiciones actuales de economía global y capitalismo moderno. Los esquemas de desarrollo económico no sobrevienen como modelos genéricos o juegos que se puedan aplicar indiscriminadamente; cada proyecto debe ser creado sobre medida para ajustarse a condiciones locales y circunstancias especiales. La propuesta delineada aquí responde directamente a los recursos particulares del norte de México relacionados con los requerimientos de un mercado específico, y no busca criticar ningún plan de desarrollo actual en la región. Aunque es poco probable que su aplicación sea tomada seriamente en consideración, tendría un valor heurístico para demostrar los tipos de variables requeridas si la planificación urbana quiere ser a la vez totalizadora y holística.

Los estados mexicanos de Sonora, Chihuahua y Nuevo León cuentan con ciudades medias en crecimiento. La población de Chihuahua, por ejemplo, se ha triplicado en veinte años para alcanzar los 600000 habitantes. Según lo que sé, México no planificó ni anticipó esta situación. La mayor parte del crecimiento se debe a la migración de las zonas rurales, atraída por las nuevas fábricas, las maquiladoras instaladas allí por inversionistas estadunidenses en busca de mano de obra barata. Los trabajadores de estas plantas ganan en promedio un dólar por hora; los más experimentados ganan alrededor de uno cincuenta (Uchitell, 1993). El reciente desarrollo industrial del norte de México ha conllevado la construcción de mejores carreteras y la formación de una fuerza de trabajo más capacitada, fortaleciendo así la posición de la región para crecer aún más (Uchitell, 1993).

Dado que una economía diversificada hace a una zona menos vulnerable a las fluctuaciones del mercado mundial y más apta para el crecimiento urbano constante, un plan de desarrollo regional busca, idealmente, introducir una diversidad de industrias que sean, también idealmente, del tipo que prometa perdurar. Establecer nuevas industrias en cualquier parte en nuestros días exige mercadotecnia; pero quien estuviese en condiciones de invertir debe ser atraído por algún ofrecimiento. La parte central del norte de México tiene muchas características sumamente deseables y ampliamente apreciadas; pero en gran medida, otras virtu- 
des son perdidas de vista a menos de que se les relacione con un mercado potencial específico. Tiene una panorámica espectacular, un clima cálido, disponibilidad de mano de obra barata, bajo costo de la vida y proximidad con el suroeste de Estados Unidos; todo esto lo convierte también en un sitio atractivo para la residencia de estadunidenses jubilados. 8

\section{El mercado de jubilados de Estados Unidos}

El segmento de la población estadunidense que crece con mayor velocidad es el de la tercera edad. Hay en la actualidad alrededor de 30 millones mayores de 65 años, cifra que pronto llegará a los 40 millones (Barringer, 1993). Muchos de ellos tienen ingresos por jubilación que les proporcionan un estilo de vida acomodado, y muchos se han mudado de ciudades del norte para vivir en los sureños estados del "cinturón solar" (véase, por ejemplo, Jacobs, 1974). Bastantes mantienen dos residencias, una de invierno en el sur, y otra de verano en el norte. La gente de edad avanzada de Estados Unidos constituye un amplio mercado que duplicará su tamaño a lo largo de la próxima década, según aumente el número de personas que tome su jubilación anticipada. El norte de México tiene una localización privilegiada para capturar parte de esta población. Su posición geográfica lo hace competitivo con áreas de retiro al norte de la frontera. Ciudades como Hermosillo, Monterrey, Chihuahua y Saltillo están a menos de $\mathbf{3 0 0}$ millas de la línea internacional (seis horas de camino en coche sobre una buena carretera) y a unas cuantas horas, por avión, de muchas ciudades estadunidenses. Algunas, como Chihuahua, ya tienen una apariencia arquitectónica atractiva de fábricas modernas contrastantes con un impresionante paisaje montañoso. La fuerza de trabajo bien capacitada de la región constituye una clase media más dispuesta a hablar inglés y a apoyar los tipos de servicios que desean los estadunidenses. Así, la apariencia de las ciudades de la región y su población es idónea para éstos.

Ahora es el momento propicio para promover este negocio, dadas las condiciones de los estados del cinturón solar. Arizona tiene poca agua. Todos sus mantos superficiales están ya asignados, y muy probablemente se restrinja la explotación de los man-

${ }^{8}$ Como suele suceder, los descubrimientos de unos son anticipados por otros, en este caso por las fuerzas del mercado. Arthur Murphy me dice que sabe de la existencia de tales comunidades de jubilados establecidas recientemente en las dos costas norteñas del Golfo de California. 
tos subterráneos de este estado por motivos ecológicos. A falta de nuevas fuentes acuíferas, la población ha llegado a su límite de expansión. Es muy probable que prevalezcan las consideraciones ambientales para restringir proyectos urbanos en otras zonas, como en Florida y el"sur de California. Estos dos estados tienen una imagen problemática por el temor a huracanes, terremotos y violencia criminal. Los jubilados se sentirían más seguros en Texas o Nuevo México, dos regiones que probablemente experimenten un crecimiento de las comunidades de jubilados. 9

La idoneidad del momento tiene también su lado negativo ante la urgencia de actuar antes de que disminuyan las oportunidades y se pierdan las ventajas. Aunque el costo de la vida en México sigue siendo menor al de Estados Unidos, se ha incrementado rápidamente, mermando así el atractivo del país a ojos de los estadunidenses como opción barata para vivir.

Se necesitan inversiones en infraestructura antes de que empiece a fluir el río de jubilados del país del norte. Su visión de la potabilidad del agua mexicana requiere de una solución de ingeniería junto con una estrategia de administración de la imagen que se da. Las preocupaciones de salubridad, como los desagües y la sanidad, también exigen atención. La mayoría de la gente de edad avanzada no padece problemas graves de salud; no obstante, esta población toma una parte desproporcionadamente grande del costo de la salud social de Estados Unidos. Invertir para garantizarles instalaciones médicas satisfactorias es de importancia crítica. Hacerlo podría redundar en una industria sanitaria especializada en atender a estadunidenses, contando con que el alto costo de la atención médica en Estados Unidos difícilmente se reducirá de manera significativa con las actuales metas de reforma.

Los habitantes del país del norte viven más, y los de la tercera edad son más activos. La recreación atlética es importante para ellos, de modo que se necesitarán instalaciones deportivas diseñadas para una población de edad avanzada -como canchas de tenis, campos de golf y, cuando se pueda, lagos para pescar y andar en lancha. También requieren de buenas autopistas y aeropuertos, dado que, aparte de la transhumancia anual norte-sur de nucha gente, viajan y reciben visitas de amigos, antiguos colegas, hijos y nietos. Es posible imaginar otras obras para aumentar el

9 El estado de Texas presenta una desventaja. Se están inaugurando nuevas plantas eléctricas en el noreste de México. Funcionan a base de lignita, carbón de baja calidad, de modo que podrían enrarecer amplias masas del aire de Texas. Está en duda si México utilizaría la amenaza de estas centrales para negociar su acceso a más agua proveniente del río Colorado. 
atractivo de la zona, como la construcción o el mejoramiento de estadios de besibol donde jueguen equipos mexicanos, pero quizá también estadunidenses, durante el entrenamiento primaveral.

Indudablemente, no he anticipado muchas objeciones que ha de haber a esta propuesta. Aunque he tratado de ser objetivo al considerar sus ventajas y limitaciones, naturalmente preferí centrarme en los rasgos atractivos. Éstos incluyen una situación favorable a México en términos de la balanza de pagos. El asentamiento de miles de estadunidenses en el norte de México seguramente tendría efectos multiplicadores en la economía; igual que los turistas, traerían dólares para gastar localmente; pero, a diferencia de éstos, gastarían mucho en bienes caros, como condominios, casas, carros, muebles y electrodomésticos. No competirían con los mexicanos por los trabajos y generarían actividades de trabajo intensivas en mano de obra en la industria de la construcción y los servicios, la mayoría de las cuales serían, aparentemente, de propiedad mexicana. La acción concomitante de todo lo anterior debería estimular el desarrollo de nuevos proyectos urbanos para aumentar servicios e instalaciones que harían aún más atractiva al norte de México, la inversión internacional para emplazar nuevas fábricas y oficinas regionales y subsidiarias.10

Ningún negocio se hace sin riesgos ni costos. Los antropólogos, por supuesto, deberían anticipar ante todo algunos costos intangibles. El agringamiento del norte de México puede ser problemático, por ejemplo, si se le ve como una amenaza al honor o la integridad nacional mexicanos. Los nacionalistas podrían llegar a explotar la creciente presencia de estadunidenses y su cultura en tierras mexicanas para obtener ventajas políticas. Los problemas físicos en la región ya se están poniendo de manifiesto con los cinturones de miseria.

Se puede interpretar que el crecimiento rápido de las ciudades mexicanas del norte está fuera de control y que algunas ciudades podrían avanzar hacia el rango de megaciudades. De ser así, la situación se puede manejar mediante intervenciones juiciosas que determinen la localización de nuevos proyectos de desarrollo. El gobierno sigue siendo el árbitro final respecto a la definición de dónde se realizarán las mejoras de infraestructura, la construcción de caminos, puentes y aeropuertos, así como la crea-

10 En la economía global de la actualidad, las escisiones de las corporaciones multinacionales respecto de la localización de nuevas oficinas regionales, fábricas y centros de distribución -y las operaciones de acabado en instalaciones existentes- se basan de manera compleja en muchísimos factores, y no todos son racionales en estricto sentido económico (Pred, 1977). 
ción de ductos para agua y drenaje, etcétera. Con creatividad, el gobierno puede determinar dónde se concentrará el desarrollo urbano o si será disperso y en qué lugares. Además, el gobierno puede controlar los sitios de los proyectos estableciendo una variedad de sociedades con inversionistas privados. La forma moderna de hacér negocios en la construcción urbana requiere de cantidades enormes de inversión de capital, como en la construcción de comunidades para jubilados, por lo que los gobiernos están en una situación favorable para probar los límites de su poder; pero a menudo se rehusan a hacerlo.

El crecimiento urbano descontrolado aparece con la extensión de asentamientos irregulares en las nuevas ciudades industriales del norte de México y en algunas áreas en que el turismo ha adquirido importancia. Los asentamientos irregulares representan un problema serio porque no tiene sentido traer migrantes a una zona si no pueden disfrutar un mejoramiento significativo en su calidad de vida. Garantizar esa mejora se hace más difícil, retrasándose aún más a veces, ya que el crecimiento de los asentamientos irregulares rara vez coincide con los planes de las dependencias gubernamentales. Los gobiernos pueden garantizar vivienda satisfactoria para migrantes de ingresos bajos y medios y servicios urbanos decentes siguiendo las pautas de situaciones similares en muchas partes de Estados Unidos.11

Si la estrategia de desarrollo propuesta aquí logra atraer migrantes mexicanos provenientes del Distrito Federal, constituiría una solución temporal si se le ve a escala realmente histórica. No se requiere ser malthusiano para reconocer que, incluso con los avances tecnológicos que podamos predecir para el siglo próximo que propicien ciudades de 30 a 50 millones de habitantes, el planeta no puede sostener un crecimiento ilimitado de la población humana.

${ }^{11}$ San Francisco, California, fue uno de los primeros municipios en imponer cuotas a la construcción de rascacielos para apoyar guarderías, servicios culturales, transporte público y la construcción de vivienda para gente con ingresos bajos y medios (Smith, 1985). Los constructores de Battery Park en la parte baja de Manhattan, Nueva York, debieron proporcionar fondos para la construcción o renovación de vivienda para gente de ingresos bajos. Esas exigencias a los constructores de Estados Unidos forman parte de un ámbito de negociación, existente desde hace un par de décadas, para garantizar la construcción de parques, tiendas y restaurantes a cambio de eliminar restricciones al código de altura, volumen y setbacks (revestimientos o espacios libres al frente de las construcciones). 


\section{Conclusiones: los límites del preámbulo}

El presente ensayo inició con la búsqueda de una definición clara y útil de lo que significa el tamaño medio, cuando se aplica a ciudades, suponiendo que las llamadas medias tienen que ver con la solución de los problemas de la ciudad de México. Es decir, además de otras virtudes, los planificadores urbanos han sentido que las ciudades medias pueden constituir una forma para atraer residentes, sacándolos de las megaciudades, y de allí el doble sentido del término "atractivo" utilizado en el título del presente texto. Una revisión breve de los esfuerzos recientes por crear ciudades medias para disminuir la presión de la población, indicaba que los incentivos económicos constituyen los determinantes principales de las decisiones de reubicación residencial. Entonces, basado en la geografía y otros factores, argumentaba que las ciudades medias del norte de México tienen un potencial de crecimiento urbano con la introducción de una nueva industria, la de comunidades de jubilados estadunidenses.

Sólo un análisis de mercado puede determinar si cruzar la frontera entre México y Estados Unidos constituye una barrera psicológica para los habitantes de este país o si la propuesta no es realizable por otros motivos. De cualquier modo, deben contratar antropólogos para que les ayuden con su investigación, ya que muchas de las variables desconocidas competen a la investigación antropológica. Esto nos lleva a una consideración final, la de la función cambiante de los especialistas urbanos, y a otra frontera, la que distingue diferentes áreas del conocimiento académico.

Una vieja canción dice que los tontos se precipitan adonde los ángeles temen pisar, y al presentar mi boceto de estudio para encarar el tamaño de la ciudad de México, he entrado, sin el mínimo cuidado, en las áreas en que me falta competencia. Para justificar esta transgresión sin dejar de respetar las diferencias entre las disciplinas, sugiero que insistir en una división tajante en el trabajo académico, más común hace unos 30 años, crea una fricción innecesaria entre la teoría y la práctica, y ata la mente a perspectivas profesionales estrechas. Por supuesto, es riesgoso aventurarse en terrenos en que uno tiene una competencia limitada, pero ese riesgo debe ser sopesado con la posibilidad de que un pequeño aventuramiento audaz pueda llevar a ideas innovadoras y valiosas. Lo más importante, finalmente, es la contribución colectiva que podamos aportar a una mejor comprensión y un mayor control de cómo queremos que se desarrollen nuestros ámbitos urbanos. 


\section{Bibliografia}

Arriaga, Eduardo E. (1968), "Components of City Growth in Selected Latin American Countries", en The Milbank Memorial Fund Quarterly, vol. 46, núm. 2, pp. 237-252.

Barringer, Felicity (1993), "Disability Rates of Elderly Drop, Study Finds, Challenging Theory", en The New York Times, 7 de abril.

Berry, B.J.L. (1961), "City Size Distributions and Economic Development", en Economic Development and Cultural Change, núm. 9, pp. 573-588.

Castells, Manuel (1977), The Urban Question, Cambridge, mit Press.

Davis, Kingsley y Hilda Golden (1954), "Urbanization and the Development of Preindustrial Areas", en Economic Development and Cultural Change, núm. 3, pp. 6-24.

Glaab, Charles N. y A. Theodore Brown (1972), A History of Urban America, Nueva York, Macmillan.

Gottman, Jean (1961), Megalopolis, Nueva York, The Twentieth Century Fund.

Gulick, John (1989), The Humanity of Cities: An Introduction to Urban Societies, Granby, Bergin and Garvey.

Hardoy, Jorge E. (comp.) (1975), Urbanization in Latin America: Approaches and Issues, Nueva York, Anchor/Doubleday.

Harris, Walter D. Jr. (1971), The Growth of Latin American Cities, Athens, Ohio University Press.

Hartshorn, Truman A. (1992), Interpreting the City: An Urban Geography, Nueva York, John Wiley and Sons.

Jacobs, Jerry (1974), Fun City: An Ethnographic Study of a Retirement Community, Nueva York, Holt, Rinehart and Winston.

Kandel, Jonathan (1985), "Nation in Jeopardy: Mexico City's Growth, Once Fostered, Turns into Economic Burden", en The Wall Street Journal, 4 de octubre.

Laquian, Aprodicio A. (1982), "Issues and Instruments in Metropolitan Planning" en Philip M. Hauser (comp.), Population and the Urban Future, Albany, State University of New York Press.

Logan, John R. y Harvey L. Molotch (1987), Urban Fortunes: The Political Economy of Place, Berkeley, University of California Press.

Miner, Horace (1967), "The City and Modernization: An Introduction" en Horace Miner (comp.), en The City in Modern Africa, Nueva York, Frederick A. Praeger.

Mitroff, Ian I. y Harold A. Linstone (1993), The Unbound Mind: Breaking the Chains of Traditional Business Thinking, Nueva York, Oxford University Press.

Plotnicov, Leonard (1970), "Urbanism as a Cultural Concept: The City as Symbol”, Carnegie Review, núm. 22, pp. 21-26.

- (1991), "Competition and Cooperation in Contemporary American Urban Development", en City and Society, núm. 5, pp. 103-119.

Pred, Allen (1977), City Systems in Advanced Economies, Nueva York, Wiley. 
Rappaport, Roy A. (1993), "Distinguished Lecture in General Anth ropology: The Anthropology of Trouble", en American Anthropologist, vol. 95, núm. 2, pp. 295-303.

Smith, Reginald (1985), "Downtown Plan OKd on Quick 6-to-5 Vote", en San Francisco Chronicle, 7 de marzo.

Steinberger, Peter J. (1985), Ideology and the Urban Crisis, Albany, State University of New York Press.

Uchitell, Louis (1993), "America's Newest Industrial Belt: Northern Mexico Becomes a Big Draw for High Tech Plants and U.S. Jobs", The New York Times, 21 de marzo. 
$-$ 